\title{
PRODUÇÃO MAIS LIMPA NA CULTURA DO MELÃO EM PETROLINA - PE: UMA PARCERIA ENTRE A EMBRAPA SEMIÁRIDO E OS PRODUTORES LOCAIS
}

\author{
Maria de Fátima da Silva', Cícero Natanael de Oliveira Silva', Ana Regina Bezerra Ribeiro², Rebert Coelho \\ Correia $^{3}$, José Lincoln Pinheiro Araújo ${ }^{3}$
}

\author{
${ }^{1}$ Discente do programa de Pós-Graduação em Administração e Desenvolvimento Rural pela Universidade Federal Rural de \\ Pernambuco. Rua Dom Manoel de Medeiros, S/N Campus UFRPE Bloco C $1^{\circ}$ andar, Dois Irmãos, Recife - PE, 52.171-900. E-mail: \\ f4tyma.adm@gmail.com, cicerooliveirasilva@gmail.com \\ ${ }^{2}$ Docente do programa de Pós-Graduação em Administração e Desenvolvimento Rural pela Universidade Federal Rural de \\ Pernambuco. Rua Dom Manoel de Medeiros, S/N Campus UFRPE, Bloco C, $1^{\circ}$ andar, Dois Irmãos, Recife - PE, 52.171-900. E-mail: \\ arbr2008@hotmail.com \\ ${ }^{3}$ Engenheiro Agrônomo, pesquisadores da Embrapa Seminário, Rodovia BR-428, Km 152, s/n - Zona Rural, Petrolina - PE, $56302-970$. \\ E-mail: rebert.correia@embrapa.br; lincoln.araujo@embrapa.br
}

RESUMO: A expansão da agricultura irrigada no semiárido Pernambucano, utilizando tecnologias modernas tem contribuído de forma eficiente no aumento da produtividade de frutas. Este estudo buscou identificar quais as práticas de Produção Mais Limpa - P+L usadas no plantio de melão em Petrolina - PE. O método utilizado foi da pesquisa de campo com abordagem descritiva dos dados. Entende-se que o uso de princípios da P+L na cultura mostra-se eficiente quando comparado com os sistemas tradicionais de irrigação por sulco, e uso de fertilizantes por pulverização, assim, a forma de atuação vem aumentando a eficiência na produção do melão e na qualidade do produto ofertado ao mercado. Conclui-se que, o uso do mulching biodegradável, fertilizante na água, irrigação por gotejo, a adubação da terra com as folhas e ramos do melão, recolhimento das embalagens de fertilizantes e defensivos agrícola pelos fornecedores torna a cultura de melão sustentável.

Palavras-chave: Melão, sustentabilidade, Produção Mais Limpa.

\section{CLEANER PRODUCTION IN THE MELON CROP IN PETROLINA - PE: A PARTNERSHIP BETWEEN EMBRAPA SEMIARIDO AND LOCAL PRODUCERS}

ABSTRACT: The expansion of irrigated agriculture in the semi-arid Pernambucano, has contributed in an efficient way in increasing the productivity of fruits. This study aimed to identify the Cleaner Production $-P+L$ practices used in melon planting in Petrolina - PE. The method used was field research with a descriptive approach to the data. It is understood that the use of $P+L$ principles in the crop is efficient when compared to the traditional systems of irrigation by furrow, and the use of fertilizers by spraying, thus, the form of performance has increased the efficiency in the production of melon and the quality of the product offered to the market. It is concluded that the use of biodegradable mulching, fertilizer in the water, drip irrigation, fertilization of the soil with the leaves and branches of the melon and the collection of fertilizer used in the culture makes the crop sustainable.

Keywords: Melon, sustainability, cleaner production.

\section{INTRODUÇÃO}

Ao longo dos anos o Brasil vem se destacando por ser um dos maiores produtores de frutas frescas do mundo. A maior parte desta produção concentra-se na região Nordeste do país, destacando-se por produzir abacaxi, abacate, banana, caju, coco, mamão, manga, maracujá, melão, uva, acerola e goiaba (MOURA et al., 2013). Este setor tem importância socioeconômica, na medida em que absorvem as matérias-primas produzidas na região, induzindo à modernização do setor primário, crescimento dos serviços e, sobretudo, contribuindo para minimizar o impacto negativo da liberação de mão de obra para os grandes centros urbanos, através da geração de emprego e renda (DIAS, 2001).

A agricultura do semiárido pernambucano é regida pela Lei $12.787 / 2013$, que tem como um dos objetivos incentivar a ampliação da área irrigada e 
aumentar a produtividade em bases ambientalmente sustentáveis, dada a acentuada e restritiva característica do estresse hídrico em praticamente todas as bacias hidrográficas regionais (BRASIL, 2013; CASTRO, 2018).

Mesmo reconhecendo a importância socioeconômica do setor, a produção das frutas gera resíduos como: casca, caroço e/ou sementes e bagaço (MOURA et al., 2013). Assim, podem representar perda de biomassa e de nutrientes, aumento do potencial poluidor associado à disposição inadequada, que, além da poluição de solos e de corpos hídricos quando há lixiviação de compostos, acarreta problemas de saúde pública, como também contribui para o aumento do preço do produto final (ROSA et al., 2011).

Neste entendimento, Munasinghe (2014) afirma que em decorrência do aumento do consumo humano, surge cada vez mais a preocupação de produzir de forma sustentável através de técnicas e tecnologias de produções ambientalmente correta.

Neste contexto, surge a Produção Mais Limpa - P+L que tem como princípio aplicação continuada de estratégias ambientais preventiva, através da integração dos processos que contribuam com 0 aumento da eficiência no uso dos recursos: água, energia, matéria prima e mão de obra, e com a redução e/ou minimização da emissão de resíduos. Tais princípios contribuem para 0 bem-estar da sociedade e do meio ambiente (RODRIGUES; PADILHA; MATTOS, 2009).

Segundo Cericato, Meneghello e Filippin (2013) a aplicação dos princípios $\mathrm{P}+\mathrm{L}$, podem reduzir custos, e apresentar benefícios ao meio ambiente por meio da redução de desperdícios, redução dos contaminantes e diminuição da poluição durante o processo produtivo (GROSSI, 2014; MASTELLA; ROSA, 2017). Assim, 0 objetivo deste trabalho foi identificar se as práticas da Produção Mais Limpa estão sendo utilizadas em uma propriedade produtora de melão, localizada no município de Petrolina - Pernambuco.

\section{MATERIAL E MÉTODOS}

A presente pesquisa se caracteriza como um estudo de campo com enfoque exploratório e descritivo, pois visa conhecer quais as práticas da Produção Mais Limpa que estão sendo usadas no cultivo da cultura do melão, descrevendo as características do fenômeno estudado. De acordo com Gonçalves (2001, p. 67), "pesquisa de campo é o tipo de pesquisa que pretende buscar a informação diretamente com a população pesquisada e reunir um conjunto de informações a serem documentadas".

Quanto à abordagem, este estudo consolida-se a partir de uma análise qualitativa, pois tem a finalidade de compreender um determinado problema (DIEHL; TATIM, 2004).

O campo de estudo foi uma propriedade de médio porte produtora de melão, que exporta em torno de $99 \%$ de sua produção para o mercado externo (um plantio de cerca de 10 hectares de melão, com capacidade de produzir 25 toneladas por hectare, ao custo de $\mathrm{R} \$ 7.000,00$ por hectares e que também produz manga e goiaba), localizado na zona rural de Petrolina - PE.

Os sujeitos da pesquisa foram dois pesquisadores da Embrapa Semiárido - PES, e um Engenheiro Agrônomo - EA. Vale salientar, que nos resultados será usado PES para indicar os pesquisadores da Embrapa e EA para o engenheiro Agrônomo.

Como principal estratégia para coleta de dados utilizou-se uma entrevista semiestruturada, realizada no mês de julho de 2018.

\section{RESULTADOS E DISCUSSÃO}

A cultura do melão em análise é do tipo pele de sapo, produzido para atender ao mercado externo. 0 produtor tem como estratégia para baratear o custo a entrega das frutas na propriedade. Assim, quando o melão cumpre o ciclo da produção, os funcionários fazem a colheita separadamente por tamanho e os embalam dentro dos containers, que saem da produção diretamente para o porto do Ceará.

Em relação à utilização dos princípios de Produção Mais Limpa - P+L, foram feitas as seguintes perguntas: Quais as ações sustentáveis que o produtor está usando para não agredir o meio ambiente? A resposta foi a seguinte: "É feita a irrigação por gotejamento, utilizando apenas 20 litros de água por dia, antes eram gastos em média 200 litros por dia. É feito o uso de manta plástica biodegradável que dura no máximo 90 dias para decompor no solo. Há a reutilização da manta por duas colheitas, que depois é retirada e queimada em um local adequado, distante 
da plantação e da zona urbana. Também é feita a utilização das folhagens e ramagem como adubo na plantação entre uma colheita e outra" (EA, 2018).

Em seguida, foi perguntado sobre o volume de exportação, o mesmo respondeu que é exportado em média $99 \%$ de todo melão produzido. Dando continuidade a entrevista foi questionado sobre quais as estratégias utilizadas no uso de insumo. Ele respondeu: "Quanto ao uso de fertilizante, que antes era feito por pulverização, passou a ser inserido na água, evitando o desperdício de material, como também a planta recebe a quantidade adequada através do gotejamento, que é um sistema de irrigação inteligente, onde varia a quantidade irrigada de acordo com a temperatura e desenvolvimento do meloeiro, retendo ou liberando a quantidade de água necessária para a planta" (EA, 2018).

Outra questão procurou identificar se o produtor tinha sistema de recolhimento das embalagens dos agrotóxicos utilizados na produção. 0 engenheiro respondeu: "Sim, toda embalagem usada na cultura são levadas para um deposito onde é feita a coleta de lixo de acordo com o tipo dos resíduos" (EA, 2018).

Neste contexto, percebe-se que o produtor tem a preocupação com o meio ambiente ao fazer a coleta seletiva de lixo bem como não deixar na natureza os resíduos de difíceis de decompor. Após a entrevista com engenheiro agrônomo foi realizada uma entrevista semiestruturada ao Setor Econômico da Embrapa Semiárido.

A quarta questão foi sobre como a Embrapa tem atuado para auxiliar os produtores quanto à redução dos danos ao meio ambiente, o funcionário respondeu: "A Embrapa tem auxiliado os produtores através de pesquisa e desenvolvimento, disponibilizando tecnologia e capacitando os produtores. Assim, a Embrapa testa a tecnologia e transfere para os produtores. Um exemplo é a irrigação por gotejamento, que tem reduzido o consumo de água em 90\%" (PES, 2018).

Entendendo que a água é um dos bens naturais mais preciosos para a humanidade, seu uso sustentável, através da eliminação de desperdícios, é de grande relevância para a realização de qualquer produção. Assim, esta nova forma de produção agrícola tem contribuído para conservação do meio ambiente, como também tem proporcionado mais eficiência no uso dos recursos e das matérias-primas. Essa eficiência é resultado da parceria entre produtores, Embrapa e Chesf, a partir de um projeto, denominado "Lago de Sobradinho". O produtor participa com a mão de obra e por meio do projeto, além de capacitá-los, adquire todos os insumos e sistema de irrigação e implanta na propriedade do mesmo. A produção fica com o produtor.

A quinta pergunta estava relacionada aos Campos de Aprendizagem Tecnológica (CATs) e quais eram as culturas que receberam o programa. E a resposta foi a seguinte: "Inicialmente o projeto atendeu os produtores de melão, melancia e cebola [...] os CATs superaram as expectativas ao atender 88 produtores, superando em $10 \%$ as metas previstas, que era de 80 produtores dos municípios do entorno do Lago de Sobradinho" (PES, 2018).

Acrescentando a pergunta sobre o programa de Campos de Aprendizagem Tecnológica (CATs), a sexta pergunta foi sobre quais os impactos realizados no semiárido após a implantação do programa, o pesquisador afirmou que: "é visível a considerável mudança econômica e social ao entender que os produtores, pois além de receberem os benefícios do projeto, também absorveram as orientações técnicas para aplicar no dia a dia da produção, aumentando a eficiência produtiva e, assim, tornando-os mais competitivos" (PES, 2018).

Seguindo a entrevista, a sétima pergunta enfatizava sobre quais os principais ganhos obtidos com as tecnologias disponibilizadas pela Embrapa aos produtores, foram listadas as seguintes vantagens:

Aumento da produtividade e a redução de custo de produção, como, por exemplo, a economia de $80 \%$ da água usada na irrigação por meio do sistema de gotejamento na cultura de melão, melancia e cebola;

Diminuição do uso de fertilizantes, e

Melhoria da quantidade e qualidade dos frutos (EA, 2018).

É percebido que o uso dos princípios $\mathrm{P}+\mathrm{L}$ no plantio de melão mostra-se eficiente quando comparado com os sistemas tradicionais de irrigação por sulco e fertilizantes a lanço. Neste sentido, essa forma de atuação no cultivo meloeiro vem contribuindo para o aumento da eficiência na produção do melão e a qualidade do produto final. 


\section{CONCLUSÕES}

Existe 0 uso de princípios da Produção Mais Limpa, estando em destaque 0 uso de mulching biodegradável, uso de fertilizante na água, irrigação por gotejo reduzindo $80 \%$ do uso da água, adubação orgânica da terra utilizando folhas e ramos do melão e o recolhimento das embalagens de agroquímicos usados na cultura.

Em relação à parceria entre a Embrapa Semiárido e os produtores é percebido que a mesma tem contribuído de forma efetiva. Também foi verificado que as contribuições fornecidas pela Embrapa auxiliam na construção do objetivo da Produção Mais Limpa por disponibilizar aos produtores conhecimentos e tecnologias que aumentam a eficiência na utilização dos recursos e evitam ao máximo o desperdício de insumos nas produções, consequentemente preservação ambiental.

Percebe-se com essa pesquisa que a Embrapa Semiárido teve um papel muito importante para a propriedade analisada, e outras que vem utilizando as orientações técnicas, visto que os conhecimentos e procedimentos repassados aos produtores contribuíram para melhorar os procedimentos realizados na plantação, impulsionando a melhoria na eficácia do uso da matéria prima, ganho financeiro pela redução do uso de fertilizante, água e mão de obra, além de maior competitividade de mercado pela qualidade do produto final e a redução dos custos, além da contribuição ambiental através da eliminação e redução do impacto ambiental.

\section{AGRADECIMENTOS}

À Coordenação de Aperfeiçoamento de Pessoal de Nível Superior - CAPES pelo apoio financeiro e a Embrapa Semiárido, em especial aos professores Rebert Coelho Correia e José Lincoln Pinheiro Araújo, pela contribuição na construção desse trabalho.

\section{REFERÊNCIAS}

BRASIL, Lei 12.787/2013. Dispõe sobre a Política Nacional de Irrigação; altera 0 art. 25 da Lei no 10.438, de 26 de abril de 2002; revoga as Leis nos 6.662, de 25 de junho de 1979, 8.657, de 21 de maio de 1993, e os DecretosLei nos 2.032, de 9 de junho de 1983, e 2.369, de 11 de novembro de 1987; e dá outras providências. Diário Oficial da União, Brasília, p. 4, 14 jan. 2013. Disponível em: http://www.planalto.gov.br/ccivil_03/_ato2011-2014/2013/ lei/12787.htm. Acesso em: 07/09/2018.

CASTRO, C. N. de. Sobre a agricultura irrigada no semiárido: uma análise Histórica e atual de diferentes Opções de política. 2018. IPEA Instituto de Pesquisa Econômica Aplicada - Brasília: Rio de Janeiro: Ipea, 1990- ISSN 1415-4765. Disponível em: file:///C:/Users/ Joana\%20Daddd/Downloads/TD_2369.pdf> acesso em 03/09/2018.

CERICATO, A.; MENEGHELLO, G.; FILIPPIN, I. Produção mais limpa em Agroindústrias: uma análise da estrutura de pequenas agroindústrias dos setores de carne e leite. Revista Unoesc \& Ciência - ACSA, 2013, 4, 185-202.

DIAS, M. do C. O. (coord.) et al. Manual de impactos ambientais: orientações básicas sobre aspectos ambientais de atividades produtivas. Fortaleza: Banco do Nordeste, 2001. 297p.

DIEHL, A. A; TATIM, D. C. Pesquisa em ciências aplicadas: métodos e técnicas. São Paulo: Prentice Hall, 2004.

GONÇALVES, E. P. Iniciação à pesquisa científica. Campinas, SP: Editora Alínea, 2001.

GROSSI, M. Não podemos ficar atrás na busca por um modelo de desenvolvimento mais sustentável. Conselho Empresarial Brasileiro para o Desenvolvimento Sustentável, 2014.

MASTELLA, D. T.; ROSA, L. C. da. Práticas de produção mais limpa no aproveitamento de resíduos agrícolas desenvolvimento de compósito. Monografia. Centro de Tecnologia da Universidade Federal de Santa Maria, 2017.

MOURA, L. B.; FREIRE, D. S.; ROCHA, I. da S.; SILVA, J. C. I. da; SANTOS, T. V. Gerenciamento de resíduos em empresas do setor hortifrúti localizadas na região do Cariri - Ceará. Revista Verde de Agroecologia e Desenvolvimento Sustentável. 2013. 8, 21-24.

MUNASINGHE, M. Can sustainable consumers and producers save the planet? Journal of Industrial Ecology, 2014, 14, 4-6. 
RODRIGUES, R. G.; PADILHA, A. C. M.; MATTOS, P. Princípios da Produção Mais Limpa na cadeia produtiva do biodiesel: análise no elo da indústria de óleo vegetal e usina de biodiesel. Anais... In: $47^{\circ}$ SOBER Sociedade Brasileira de Economia, Administração e Sociologia Rural, Porto Alegre, 26 a 30 de julho de 2009. Disponível em: <http://www.sober.org.br/palestra/13/106.pdf>. Acesso em 07/09/2018.
ROSA, M. F.; SOUZA FILHO, M S. M.; FIGUEIREDO, M. C. B.; MORAIS, J. P. S.; SANTAELLA, S.T.; LEITÃO, R.C. Valorização de resíduos da Agroindústria. Anais... In: II Simpósio Internacional sobre Gerenciamento de Resíduos Agropecuários e Agroindustriais - SIGERA, 2011 - Foz do Iguaçu, PR disponível em: <http://www. sbera.org.br/2sigera/obras/p12.pdf>. Acesso em: 07/09/2018. 